\title{
Feasibility of Day Surgery in Patients With Breast Conservation and Sentinel Node Biopsy : A Randomized Controlled Trial
}

\section{Ojala, K.}

2016-03

Ojala , K, Vironen , J H , Mattila , K, Eklund , A M , Leidenius , M H K \& Meretoja , T J 2016 , ' Feasibility of Day Surgery in Patients With Breast Conservation and Sentinel Node Biopsy : A Randomized Controlled Trial ', Scandinavian Journal of Surgery , vol. 105 , no. 1 , pp. 29-34 . https://doi.org/10.1177/1457496915583201

http://hdl.handle.net/10138/161335

https://doi.org/10.1177/1457496915583201

publishedVersion

Downloaded from Helda, University of Helsinki institutional repository.

This is an electronic reprint of the original article.

This reprint may differ from the original in pagination and typographic detail.

Please cite the original version. 


\title{
FEASIBILITY OF DAY SURGERY IN PATIENTS WITH BREAST CONSERVATION AND SENTINEL NODE BIOPSY: A RANDOMIZED CONTROLLED TRIAL
}

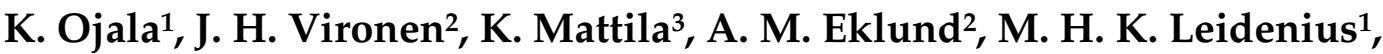 \\ T. J. Meretoja ${ }^{1}$ \\ ${ }^{1}$ Breast Surgery Unit, Comprehensive Cancer Center, Helsinki University Hospital, Helsinki University, \\ Espoo, Finland \\ 2 Department of Surgery, Jorvi Hospital, Helsinki University Hospital, Helsinki University, Espoo, Finland \\ ${ }^{3}$ Department of Anesthesiology, Jorvi Hospital, Helsinki University Hospital, Helsinki University, Espoo, \\ Finland
}

\section{ABSTRACT}

Background and Aims: The aim of this study was to analyze feasibility of day surgery in breast cancer patients with breast conserving surgery and sentinel node biopsy.

Material and Methods: The study was a randomized controlled trial comparing day surgery with one night hospital stay in breast cancer patients with breast conserving surgery and sentinel node biopsy. A total of 40 patients with $\leqslant 3-\mathrm{cm}$ tumor and clinically No were randomized to one night stay group and 38 patients to day surgery group. Within discharge, patients and their relatives were given questionnaires in order to evaluate their experience regarding the duration of hospital stay.

Results: Randomized groups were similar regarding patient age and tumor stage. A total of $18(47 \%)$ day surgery group patients were discharged the same day. The most common reason for overnight hospital stay was axillary clearance, $9(24 \%)$. None of the patients in the day surgery group, but 2 patients in the overnight hospital stay group had re-operation due to complications. Perception and preference results were analyzed both according to randomization and actual treatment groups. Patients in both groups had rather similar experiences on the first postoperative day. Also, spouse's or relative's perception after discharge was similar in both groups.

Conclusion: Day surgery was well received by the patients and their relatives. Day surgery appears as feasible in patients with breast conservation and sentinel node biopsy.

Key words: Breast cancer; day surgery; breast conserving surgery; sentinel node biopsy

Correspondence:

Kaisu Ojala

Breast Surgery Unit

Comprehensive Cancer Center

Helsinki University Hospital

Helsinki University

PL 263

00029 HUS

Finland

Email: kaisu.ojala@hus.fi
Scandinavian Journal of Surgery

2016, Vol. 105(1) 29-34

(c) The Finnish Surgical Society 2015

Reprints and permissions:

sagepub.co.uk/journalsPermissions.nav

DOI: $10.1177 / 1457496915583201$

sjs.sagepub.com

(S)SAGE 


\section{INTRODUCTION}

Over the last decades, surgical treatment of breast cancer has become less invasive. More patients are likely to receive breast conserving surgery (BCS) as tumors are found earlier and smaller, whereas larger tumors may be operated utilizing oncoplastic BCS methods. Sentinel node biopsy (SNB) has replaced axillary lymph node dissection (ALND) in axillary staging. $\mathrm{BCS}$ and SNB seem suitable procedures for day surgery. A few studies have been carried out to evaluate the safety of day surgery in patients with BCS and SNB (1-4). These studies have reported acceptable complication and hospital re-admission rates after day surgery $(1,5,6)$.

Physical recovery after SNB is faster when compared with ALND (7). Not only physical recovery, but also psychological and social recovery after breast cancer surgery is important. BCS itself has possibly reduced both early and late psychological implications of the disease $(8,9)$. However, the patient's preferences and perceptions regarding day surgery have not been widely evaluated $(1,10)$.

The aim of this study is to compare safety as well as physical and psychological symptoms between day surgery and overnight stay in patients undergoing BCS and SNB, in a randomized controlled study setup.

\section{MATERIAL AND METHODS}

In this randomized controlled trial, we compared day surgery with one night hospital stay in breast cancer patients having BCS and SNB, with the following inclusion criteria:

1. Preoperative diagnosis of breast cancer suitable for BCS and SNB;

2. Clinical tumor size of $\leqslant 3 \mathrm{~cm}$ and clinical N0 status;

3. Patient eligible for day surgery (general health), American Society of Anesthesiology (ASA) class I-II;

4. Patient accepting day surgery.

All patients received intraoperative analyses on the SNB with the plan to proceed with ALND if nodal disease was present. Patients randomized to the day surgery group were discharged on operation day if criteria were still met and their condition allowed it. Criteria for day surgery discharge on the operation day were as follows:

1. BCS and SNB without drainage;

2. Stable blood pressure and pulse level;

3. No respiratory problems;

4. Patient mobilized to the preoperative level;

5 . No or only mild nausea;

6. Postoperative pain controlled by oral pain medication, either nonsteroidal anti-inflammatory drug (NSAID), or paracetamol, or paracetamol-codein;

7. No or minimal postoperative bleeding;

8. Normal urination;

9. Adult companion at home;

10. Patient being first on the operation schedule.
General anesthesia was induced with propofol and fentanyl and maintained with propofol and remifentanil infusions. All patients were intubated and received rocuronium for muscle relaxation. Dexamethasone and granisetron were given for prophylaxis of postoperative nausea and vomiting. For treatment of pain at home, ibuprophen and paracetamol or paracetamol with codeine were prescribed.

For possible postoperative problems, detailed instructions and contact information were given within discharge. Patients were able to return to hospital and stay at breast surgery ward overnight. Patients in the overnight hospital stay group were usually discharged on the first postoperative day.

Within discharge, patients with SNB, but without ALND $(\mathrm{N}=61)$ and their spouses or other relatives received questionnaires evaluating their perception of day surgery as well as physical and psychological symptoms. The questionnaires were not validated. The questionnaires were filled on the first postoperative day and returned by mail. Two types of questions were used: those with four alternatives (i.e. 1 =none, 2 =only little, $3=$ quite much and $4=$ very much) and those with yes or no alternatives.

Results were analyzed according to original randomized groups and per protocol, that is, according to actual treatment groups. In actual treatment groups, patients were classified into day surgery group or overnight stay group by actual treatment received, regardless of original randomization. For statistical analyses, chi-squared test and MannWhitney $U$ test were used. Four graded answers were categorized into binomial variables for statistical analyses, so that alternatives 1 and 2 were combined as well as alternatives 3 and 4 . Statistical analyses were performed using SPSS version 21 statistical software.

The study plan was accepted by the Ethics Committee of Helsinki University Central Hospital. Written informed consent was obtained from all patients.

\section{RESULTS}

A total of 85 women receiving breast cancer surgery at the Jorvi Hospital, Helsinki University Central Hospital, Finland, between January 2008 and March 2011 were randomized to the day surgery group $(\mathrm{N}=40)$ or to the overnight stay group $(\mathrm{N}=38)$. Altogether, 7 patients were excluded from the study. Randomization data of 5 patients were missing, and 2 patients were not eligible because mastectomy was planned due to large tumor size after initial randomization, Fig. 1.

Results were analyzed according to randomization and also according to actual treatment received, that is, per protocol. Questionnaire results were analyzed from patients receiving $\mathrm{BCS}$ and $\mathrm{SNB}(\mathrm{N}=44)$.

A total of $18(47 \%)$ patients randomized to day surgery group were discharged the same day, whereas 20 $(53 \%)$ stayed at least one night in hospital (Fig. 1). The most common reason for overnight hospital stay was ALND (9 patients). The other reasons included drainage (1 patient), patient's wish for overnight stay after 
surgery (1 patient), and not being first on operation schedule (1 patient). Day surgery criteria in study protocol were not met in 6 patients. Reason for overnight stay was missing in 2 patients (Fig. 1). Altogether, 60 patients stayed one night or longer in hospital; 40 randomized to overnight stay and 20 randomized to day surgery group.

Randomized groups were similar regarding patient age, histological tumor size, and nodal stage (Table 1). When comparing actual treatment groups, patients who were discharged on the operation day were all node negative, because of the study design (Table 2).

None of the patients randomized to day surgery underwent re-operations due to complications. Two patients randomized to overnight stay had re-operations due to postoperative bleeding; the hematoma evacuations were performed during the same hospi-

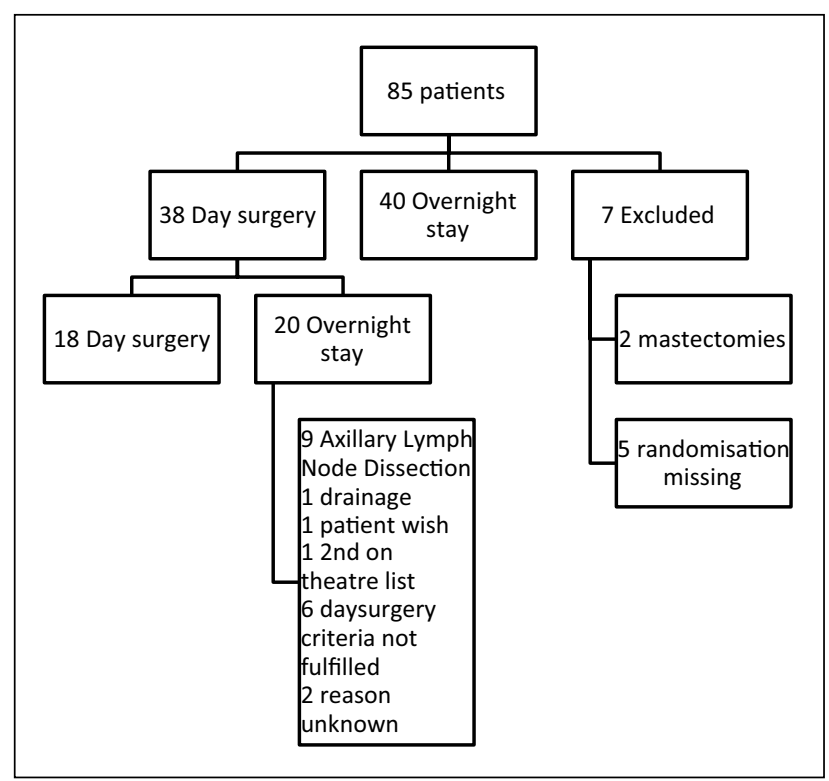

Fig. 1. Patient randomization and actual treatment. talization as the primary surgery. Hospital stay was prolonged for 3 days due to postoperative bleeding and hematoma evacuation in one patient randomized to overnight stay (Tables 1 and 2).

Altogether, $44(72 \%)$ patients returned the questionnaires, including 20 patients randomized to day surgery and 24 patients randomized to overnight stay group. When analyzed according to actual treatment, 18 patients returning the questionnaires were treated on day surgery group and 26 on the overnight stay group. All questions were answered in only 14 questionnaires. Questionnaire results are shown in Tables 3 and 4 for actual treatment groups, respectively. When analyzed according to intention to treat, no significant differences were found.

All patients who were randomized to day surgery and were treated accordingly would choose day surgery in the future. Similarly, their spouses' or relatives' perception of day surgery was positive. The majority of patients randomized to overnight stay $(67 \%)$, or who had stayed overnight regardless of randomization $(61 \%)$, would not choose day surgery in the future; $p<0.0001$ between day surgery and overnight stay, both for randomized groups and actual treatment groups.

Patients in both groups had rather similar experiences on the first postoperative day. Patients reported receiving enough information and support, without difference between groups when analyzed according to actual treatment $(\mathrm{p}=0.789$ and $\mathrm{p}=0.228)$. Also, spouse's or relative's perception after discharge was similar in both groups (Tables 3 and 4).

\section{DISCUSSION}

This randomized study shows that early patient satisfaction after BCS is equally good in day surgery patients as in patients with overnight stay. Patients received adequate information about their disease, received counseling and emotional support in both groups. Lack of emotional support was not reported as a reason for overnight stay. In our study, also

TABLE 1

Randomized groups; 78 patients.

\begin{tabular}{|c|c|c|c|c|}
\hline & & Day surgery, $N=38$ & Overnight stay, $\mathrm{N}=40$ & p-value \\
\hline Age, median (range) & & $55(40-68)$ & $57(44-69)$ & 0.426 \\
\hline Tumor size (mm), median (range) & & $12.3(1-30)$ & $13.3(4-75)$ & 0.827 \\
\hline Breast surgery & Breast conservation & $38(100 \%)$ & $40(100 \%)$ & \\
\hline \multirow[t]{2}{*}{ Axillary surgery } & SNB & $29(76 \%)$ & $32(80 \%)$ & 0.694 \\
\hline & $\mathrm{SNB}+\mathrm{ALND}$ & $9(24 \%)$ & $8(20 \%)$ & \\
\hline \multirow[t]{2}{*}{ Histological nodal stage } & No & $29(76 \%)$ & $32(80 \%)$ & 0.694 \\
\hline & N1 & $9(24 \%)$ & $8(20 \%)$ & \\
\hline \multirow[t]{5}{*}{ Hospital nights } & 0 & $18(47 \%)$ & 0 & 0.000 \\
\hline & 1 & $17(45 \%)$ & $36(90 \%)$ & \\
\hline & 2 & $1(3 \%)$ & $2(5 \%)$ & \\
\hline & 3 & $1(3 \%)$ & $2(5 \%)$ & \\
\hline & 4 & $1(3 \%)$ & 0 & \\
\hline Re-operation due to complication & & $0(0 \%)$ & $2(5 \%)$ & 0.157 \\
\hline
\end{tabular}

SNB: sentinel node biopsy; ALND: axillary lymph node dissection. 
TABLE 2

Actual treatment groups; 78 patients.

\begin{tabular}{|c|c|c|c|c|}
\hline & & Day surgery, $\mathrm{N}=18$ & Overnight stay, $\mathrm{N}=60$ & $\mathrm{p}$-value \\
\hline Age, median (range) & & $56(45-68)$ & $56(40-69)$ & 0.841 \\
\hline Tumor size (mm), median (range) & & $10.9(1-30)$ & $13.4(4-75)$ & 0.140 \\
\hline Breast surgery & Breast conservation & $18(100 \%)$ & $60(100 \%)$ & \\
\hline \multirow[t]{2}{*}{ Axillary surgery } & SNB & $18(100 \%)$ & $44(72 \%)$ & 0.011 \\
\hline & $\mathrm{SNB}+\mathrm{ALND}$ & $0(0 \%)$ & $17(28 \%)$ & \\
\hline \multirow{2}{*}{$\begin{array}{l}\text { Histological nodal } \\
\text { stage }\end{array}$} & No & $18(100 \%)$ & $44(72 \%)$ & \\
\hline & N1 & $0(0 \%)$ & $17(28 \%)$ & \\
\hline \multirow[t]{5}{*}{ Hospital nights } & 0 & $18(100 \%)$ & 0 & $<0.001$ \\
\hline & 1 & 0 & $53(88 \%)$ & \\
\hline & 2 & 0 & $3(5 \%)$ & \\
\hline & 3 & 0 & $3(5 \%)$ & \\
\hline & 4 & 0 & $1(2 \%)$ & \\
\hline Re-operation due to complication & & 0 & $2(3 \%)$ & 0.501 \\
\hline
\end{tabular}

SNB: sentinel node biopsy; ALND: axillary lymph node dissection.

TABLE 3

Questionnaire results. Actual treatment groups $(N=44)$. Percentage of answers on question.

\begin{tabular}{|c|c|c|c|c|c|}
\hline \multirow[b]{2}{*}{ Patient feels } & \multirow{2}{*}{$\begin{array}{l}\text { Day surgery } \\
\text { Not at all or little }\end{array}$} & \multirow{2}{*}{$\begin{array}{l}\mathrm{N}=18 \\
\text { Quite or very much }\end{array}$} & \multicolumn{2}{|c|}{ Overnight stay $\mathrm{N}=26$} & \multirow[t]{2}{*}{ p-value } \\
\hline & & & Not at all or little & Quite or very much & \\
\hline Tired & $13(72 \%)$ & $5(28 \%)$ & $14(54 \%)$ & $12(46 \%)$ & 0.218 \\
\hline Anxious & $18(100 \%)$ & 0 & $22(88 \%)$ & $3(12 \%)$ & 0.128 \\
\hline Nervous & $18(100 \%)$ & 0 & $23(96 \%)$ & $1(4 \%)$ & 0.381 \\
\hline Irritated & $18(100 \%)$ & 0 & $24(100 \%)$ & 0 & \\
\hline Depressed & $18(100 \%)$ & 0 & $24(96 \%)$ & $1(4 \%)$ & 0.391 \\
\hline Insecure & $18(100 \%)$ & 0 & $23(92 \%)$ & $2(8 \%)$ & 0.219 \\
\hline Desperate & $18(100 \%)$ & 0 & $25(96 \%)$ & $1(4 \%)$ & 0.400 \\
\hline Lonely & $18(100 \%)$ & 0 & $25(100 \%)$ & & \\
\hline Weak & $13(100 \%)$ & 0 & $13(93 \%)$ & $1(7 \%)$ & 0.326 \\
\hline Short of breath & $18(100 \%)$ & 0 & $25(100 \%)$ & 0 & \\
\hline Painful & $18(100 \%)$ & 0 & $22(88 \%)$ & $3(12 \%)$ & 0.128 \\
\hline Sleepless & $16(89 \%)$ & $2(11 \%)$ & $21(81 \%)$ & $5(19 \%)$ & 0.469 \\
\hline Loss of appetite & $13(87 \%)$ & $2(13 \%)$ & $15(100 \%)$ & 0 & 0.143 \\
\hline Nausea & $18(100 \%)$ & 0 & $23(92 \%)$ & $2(8 \%)$ & 0.219 \\
\hline Headache & $18(100 \%)$ & 0 & $23(92 \%)$ & $4(8 \%)$ & 0.219 \\
\hline Need of emotional support & $18(100 \%)$ & 0 & $26(100 \%)$ & & \\
\hline \multicolumn{6}{|l|}{ Spouse feels } \\
\hline Tired & $14(82 \%)$ & $3(18 \%)$ & $21(88 \%)$ & $3(12 \%)$ & 0.646 \\
\hline Anxious & $14(82 \%)$ & $3(18 \%)$ & $21(88 \%)$ & $3(12 \%)$ & 0.646 \\
\hline Nervous & $17(100 \%)$ & 0 & $21(91 \%)$ & $2(9 \%)$ & 0.212 \\
\hline Irritated & $17(100 \%)$ & 0 & $23(96 \%)$ & $1(4 \%)$ & 0.394 \\
\hline Depressed & $16(94 \%)$ & $1(6 \%)$ & $23(96 \%)$ & $1(4 \%)$ & 0.802 \\
\hline Insecure & $17(100 \%)$ & 0 & $23(96 \%)$ & $1(4 \%)$ & 0.394 \\
\hline Sleepless & $17(100 \%)$ & 0 & $23(96 \%)$ & $1(4 \%)$ & 0.394 \\
\hline Lonely & $16(94 \%)$ & $1(6 \%)$ & $21(88 \%)$ & $3(12 \%)$ & 0.482 \\
\hline Desperate & $17(100 \%)$ & 0 & $24(100 \%)$ & 0 & \\
\hline Able to support patient & $3(19 \%)$ & $13(81 \%)$ & $3(12 \%)$ & $21(88 \%)$ & 0.588 \\
\hline Able to discuss with patient & $1(6 \%)$ & $16(94 \%)$ & $2(8 \%)$ & $22(92 \%)$ & 0.767 \\
\hline $\begin{array}{l}\text { Need of more conversation } \\
\text { with patient }\end{array}$ & $16(94 \%)$ & $1(6 \%)$ & $22(92 \%)$ & $2(8 \%)$ & 0.767 \\
\hline $\begin{array}{l}\text { Need of conversation with } \\
\text { someone else }\end{array}$ & $15(94 \%)$ & $1(6 \%)$ & $19(91 \%)$ & $2(9 \%)$ & 0.718 \\
\hline
\end{tabular}

spouse's or other relative's/friend's perception was evaluated. Results showed no difference in psychological distress between these groups either.
Patient satisfaction with day surgery was high; all day surgery patients would choose day surgery in future. A total of $39 \%$ of overnight stay patients 
TABLE 4

Questionnaire results. Actual treatment groups $(N=44)$. Percentage of answers on question.

\begin{tabular}{|c|c|c|c|c|c|}
\hline & \multicolumn{2}{|c|}{ Day surgery, $N=18$} & \multicolumn{2}{|c|}{ Overnight stay, $N=26$} & \multirow[t]{2}{*}{$\mathrm{p}$-value } \\
\hline & Yes & No & Yes & No & \\
\hline $\begin{array}{l}\text { Patient feels able to talk about cancer } \\
\text { and her feelings during the first } 24 \mathrm{~h} \text { after } \\
\text { surgery }\end{array}$ & $18(100 \%)$ & 0 & $25(96 \%)$ & $1(4 \%)$ & 0.400 \\
\hline $\begin{array}{l}\text { Patient feels that she has received enough } \\
\text { support }\end{array}$ & $18(100 \%)$ & 0 & $24(92 \%)$ & $2(8 \%)$ & 0.228 \\
\hline $\begin{array}{l}\text { Patient feels that she has received enough } \\
\text { information }\end{array}$ & $17(94 \%)$ & $1(6 \%)$ & $25(96 \%)$ & $1(4 \%)$ & 0.789 \\
\hline $\begin{array}{l}\text { Patient would choose day surgery in the } \\
\text { future }\end{array}$ & $18(100 \%)$ & 0 & $10(39 \%)$ & $16(61 \%)$ & $<0.001$ \\
\hline $\begin{array}{l}\text { Patient had to contact hospital after } \\
\text { discharge }\end{array}$ & $2(11 \%)$ & $16(89 \%)$ & $1(12 \%)$ & $7(88 \%)$ & 0.919 \\
\hline $\begin{array}{l}\text { Spouse considers the length of hospital stay } \\
\text { appropriate }\end{array}$ & $17(100 \%)$ & 0 & $23(96 \%)$ & $1(4 \%)$ & $<0.001$ \\
\hline
\end{tabular}

showed interest in day surgical discharge whereas $61 \%$ would have chosen overnight stay again. In fact, patients may prefer the procedure that they have already experienced, but fear the unknown.

The rate of day surgical discharge was surprisingly low. In earlier studies, rate of discharge from day surgery in breast cancer patients has been higher, between $86 \%$ and $100 \%$ in selected study populations $(2,4-6,11)$. In our study, most common reasons for overnight stay were ALND, inability to fulfill day surgical discharge criteria, and use of drainages. Study protocol also strictly demanded day surgery patients to be first on the operation lists, which caused overnight stay in two patients randomized to day surgery. Nevertheless, none of the day surgical patients were re-admitted following discharge.

This study was started in 2008 when there was not much knowledge about day surgery in breast cancer patients. Currently, neither ALND nor drainage is a contraindication to day surgery at our unit. However, all patients with mastectomy will stay overnight. In some units, even mastectomy patients have been discharged on the operation day $(3,11)$ and with drainage. Nevertheless, ALND is not anymore routine treatment in all sentinel node positive patients (12-16). Furthermore, breast conservation may even be feasible in selected patients with multifocal tumors, due to evolution of oncoplastic techniques (17). Therefore, day surgery is a feasible option in increasing number of breast cancer patients.

This study has some limitations. The number of study patients was rather small, especially the number of those who were actually discharged on the operation day. The small number of patients may have prevented detection of some differences between the treatment groups. Approximately 400 breast cancer patients were operated annually in Jorvi Hospital and obviously all eligible patients were not recruited. Patient recruiting was lower than expected, probably because it was done parallel with busy clinical practice. Patient recruitment was terminated in 2011, before reaching predetermined 100 patients. This was due to centralization of the surgical treatment of breast cancer in Helsinki metropolitan area, that is, merging Jorvi Hospital Breast Surgery Unit with Helsinki Breast Surgery Unit. Moreover, the questionnaires were designed by the researchers and validated quality of life questionnaires were not used. Also, the response rate was rather low.

We can conclude that patient satisfaction and recovery after BCS and SNB is equal after day surgical discharge and overnight hospital stay. Day surgery was well received by patients and relatives. Day surgery appears as feasible as overnight stay regarding patient perception and satisfaction.

\section{ACKNOWLEDGEMENTS}

Clinical Trial number: NCT01613352, Agency: Clinical Trials.

\section{DECLARATION OF CONFLICTING INTERESTS}

The authors declare that they have no competing interests.

\section{FUNDING}

This research received no specific grant from any funding agency in the public, commercial, or not-for-profit sectors.

\section{REFERENCES}

1. Marla S, Stallard S: Systematic review of day surgery for breast cancer. Int J Surg 2009;7:318-323.

2. Marchal F, Dravet F, Classe JM et al: Post-operative care and patient satisfaction after ambulatory surgery for breast cancer patients. Eur J Surg Oncol 2005;31:495-499.

3. Margolese R, Lasry J: Ambulatory surgery for breast cancer patients. Ann Surg Oncol 2000;7:181-187.

4. McManus SA, Topp DA, Hopkins C: Advantages of outpatient breast surgery. Am Surg 1994;60:967-970.

5. Seltzer MH: Partial mastectomy and limited axillary dissection performed as a same day surgical procedure in the treatment of breast cancer. Int Surg 1995;80:79-81.

6. Marrazzo A, Taormina P, David M et al: Surgical treatment at early breast cancer in day surgery. Chir Ital 2007;59: 687-691. 
7. Mansel RE, Fallowfiel L, Kissin M et al: Randomized multicenter trial of sentinel node biopsy versus standard axillary treatment in operable breast cancer: The ALMANAC trial. J Natl Cancer Inst 2006;98:599-609.

8. Moyer A: Psychosocial outcomes of breast-conserving surgery versus mastectomy: A meta-analytic review. Health Psychol 1997;16:284-298.

9. Wapnir I, Cody R, Greco R: Subtle differences in quality of life after breast cancer surgery. Ann Surg Oncol 1999;6:359-366.

10. Bonnema J, van Wersch AMEA, van Geel AN et al: Medical and psychosocial effects of early discharge after surgery for breast cancer: Randomized trial. BMJ 1998;316:1267-1271.

11. Dooley WC: Ambulatory mastectomy. Am J Surg 2002;184: 545-546.

12. Giuliano AE, Hunt KK, Ballman KV et al: Axillary dissection vs no axillary dissection in women with invasive breast cancer and sentinel node metastasis. A randomized clinical trial. JAMA 2011;305:569-575.

13. Giuliano AE, McCall LM, Beitsch PD et al: Locoregional recurrence after sentinel lymph node dissection with or without axillary dissection in patients with sentinel lymph node metastases.
The American College of Surgeons Oncology Group Z0011 randomized trial. Ann Surg 2010;252:426-433.

14. Donker M, Straver ME, van Tienhoven G et al: Comparison of the sentinel node procedure between patients with multifocal and unifocal breast cancer in the EORTC 10981-22023 AMAROS trial: Identification rate and nodal outcome. Eur J Cancer 2013;49:2093-2100.

15. Straver M, Meijnen $P$, van Tienhoven $G$ et al: Sentinel node identification rate and nodal involvement in the EORTC 10981-22023 AMAROS trial. Ann Surg Oncol 2010;17: 1854-1861.

16. Galimberti V, Cole BF, Zurrida SF et al: Axillary dissection versus no axillary dissection in patients with sentinel-node micrometastases (IBCSG 23-01): a phase 3 randomized controlled trial. Lancet Oncol 2013;14:297-305.

17. Gentilini O, Botteri E, Rotmensz N et al: Conservative surgery in patients with multifocal/multicentric breast cancer. Breast Cancer Res Treat 2009;113:577-583.

Received: January 30, 2015

Accepted: March 28, 2015 